\title{
Uptake of Water Disinfection By-Products Into Food
}

\author{
James H. Raymer and Larry C. Michael
}

August 2010 


\section{About the Authors}

James H. Raymer, PhD, is a senior research analytical chemist at RTI International and directs RTI's Exposure Analysis Research Group within the Environmental and Industrial Sciences Division.

Larry C. Michael, MS, is a data manager/analyst at RTI International within the Exposure Analysis Research group.

\section{RTI Press publication MR-0016-1008}

This PDF document was made available from www.rti.org as a public service of RTI International. More information about RTI Press can be found at http://www.rti.org/rtipress.

RTI International is an independent, nonprofit research organization dedicated to improving the human condition by turning knowledge into practice. The RTI Press mission is to disseminate information about RTI research, analytic tools, and technical expertise to a national and international audience. RTI Press publications are peer-reviewed by at least two independent substantive experts and one or more Press editors.

\section{Suggested Citation}

Raymer, J.H. and Michael, L.C. (2010). Uptake of Water Disinfection By-Products Into Food. RTI Press publication No. MR-0016-1008. Research Triangle Park, NC: RTI International. Retrieved [date] from http://www.rti.org/rtipress.
This publication is part of the RTI Press Methods Report series.

RTI International

3040 Cornwallis Road

PO Box 12194

Research Triangle Park, NC

27709-2194 USA

Tel: $\quad 919.541 .6000$

Fax: $\quad 919.541 .5985$

E-mail:_rtipress@rti.org

Web site: www.rti.org
C2010 Research Triangle Institute. RTI International is a trade name of Research Triangle Institute.

All rights reserved. Please note that this document is copyrighted and credit must be provided to the authors and source of the document when you quote from it. You must not sell the document or make a profit from reproducing it.

doi:10.3768/rtipress.2010.mr.0016.1008

www.rti.org/rtipress 


\title{
Uptake of Water Disinfection By-Products Into Food
}

\author{
James H. Raymer and Larry C. Michael
}

\begin{abstract}
Humans are exposed to water disinfection by-products (DBPs) through direct ingestion of tap water and via inhalation and dermal absorption. Additional exposure from cooking foods in tap water containing DBPs has not been explored. We conducted controlled laboratory experiments to determine potential excess exposures to DBPs_-haloacetonitriles and haloacetic acids (HAAs). Some HAAs and haloacetonitriles decomposed within 10 minutes in boiling water; other analytes remained. During cooking in or contact with water, foods-frozen carrots, frozen green beans, dried pinto beans, chicken, pasta (spaghetti), and lettuce-absorbed up to 60 percent of HAA DBPs. In general, chlorodibromoacetic and tribromoacetic acids were not detected in the food after cooking. Pasta rinsed in HAA-containing spiked reagent water was shown to absorb additional HAAs and elevate the excess dietary exposure above that from cooking alone. HAA-containing tap water used to boil foods during preparation can increase the potential for human exposure, the magnitude of which depends on the types of foods cooked, the cooking duration, the volume of water used to cook the food, and the quantity of the food consumed. Regulators should consider excess dietary exposures when defining the acceptable quantities of DBPs, at least for HAAs, in tap water.
\end{abstract}

\section{Contents \\ Introduction \\ 2 \\ Methods \\ Determination of Disinfection By-Products in Water and Foods \\ Chemical Loss as a Function of Boiling Duration \\ Partition of Disinfection By-Products Into Foods During Cooking \\ Results \\ Stability of the Disinfection By-Products During Boiling 6 \\ Partition of Disinfection By-Products Into Foods During Cooking \\ Discussion

9 \\ References

Acknowledgments Inside back cover 


\section{Introduction}

The Safe Drinking Water Act mandates that the U.S. Environmental Protection Agency (EPA) identify and regulate drinking water contaminants that may have adverse health effects and are known or anticipated to occur in public water systems. Disinfection practices are changing in response to concerns about the toxicity of disinfection by-products (DBPs), which may result from the various forms of water treatment, including chlorination, chloramination, and ozonation. Some DBPs can cause adverse health effects if they are found at concentrations above specified levels of health concern. For example, DBPs have been linked to bladder cancer (Villanueva et al., 2004) and adverse pregnancy outcomes (King et al., 2004) in humans and to neurotoxicity in rats (Moser et al., 2004); in cell-based assays that use Chinese hamster ovary cells, some have been shown to be cytotoxic and genotoxic (Muellner et al., 2007).

Representative DBPs found after treatment of water with ozone, chloramine, and chlorine are shown in Table 1 (Krasner et al., 2006; Richardson, 1998; Richardson et al., 2003). After ozonation, the most abundant products are aldehydes, aldo- and ketoacids, and carboxylic acids (Krasner, 1996; Krasner et al., 2006; Nicholson, 1994; von Gunten, 2007). When bromide is in source water, it can be oxidized to hypobromous acid, which can then react with organic DBP precursors to form bromoform and other brominated organic by-products (Krasner et al., 2006).

The use of chloramine as a secondary water disinfectant can result in the production of chlorinated compounds similar to those found after the use of chlorine or chloramine alone (Krasner, 1996). Chloramine and chlorine used as disinfectants produce many of the same by-products: trihalomethanes (THMs), haloacetic acids (HAAs), and haloacetonitriles (see Table 1). In water, after chloramine treatment, these compounds generally appear at a fraction of the concentrations that they do after chlorine treatment (Symons et al., 1996).
The combinations of disinfection processes, together with the organic content of source waters, contribute to the DBPs in finished drinking water (Hua \& Reckhow, 2007). Despite the array of disinfection by-products that can be formed, only a subset are subject to regulation by EPA, including some THMs, haloacetonitriles, and HAAs.

Foods can absorb selected compounds, primarily volatile organic compounds and lead, contained in the water during cooking and food preparation. Moreover, consuming foods can contribute to a consumer's exposure to some water-based compounds and add to those exposures realized from directly drinking the water. Some foods may serve as sinks for the compounds in water (e.g., lipophilic DBPs partition into lipid components of foods: also, large amounts of water are absorbed by food during preparation; Weisel et al., 1999). Many of the foods that are suspected sinks, such as boiled meats and pasta, are consumed daily by children and other potentially high-risk individuals, such as pregnant women and older persons.

The Food Quality Protection Act of 1996 helps drive research into human exposures resulting from food contamination, such as those from contaminated drinking water. By law, these exposures must be estimated and included in risk assessments. The Food Quality Protection Act also requires that regulators consider the susceptibility of children and consider multiple pollutant exposures when those different pollutants have the same toxic endpoints.

We conducted the research reported here to determine whether ingestion of food that comes into contact with DBP-containing water increases the overall DBP exposure from directly drinking the same water. If so, the finding would suggest that the risks associated with DBPs will be underestimated if analysts include in their calculation of risk only the amounts of these compounds consumed directly from the drinking water. Thus, including both food and water contributions in the total ingestion exposure estimates from DBPs is important. 
Table 1. Major disinfection by-products found in drinking water after various treatments

Chemical Class of By-Product,

by Disinfection Process

Examples

Ozonation

\begin{tabular}{|c|c|}
\hline Inorganics ${ }^{a}$ & Bromate and hypobromate \\
\hline Aldehydes & $\begin{array}{l}\text { Formaldehyde, acetaldehyde, and propanal; glyoxal, and methyl glyoxal; } \\
\text { benzaldehyde }\end{array}$ \\
\hline Ketones & Acetone, butanone, dioxobutane, and 3-hexanone \\
\hline Carboxylic acids & $\begin{array}{l}\text { 2-methylpropanoic acid, pentanoic acid, and heptanoic acid; oxobutendioic } \\
\text { acid; benzoic acid }\end{array}$ \\
\hline Brominated organics $^{a}$ & $\begin{array}{l}\text { Bromoform (tribromomethane), dibromoacetic acid, 1,1-dibromoacetone, } \\
\text { and cyanogen bromide; dibromoacetonitrile and bromopicrin } \\
\text { (tribromonitromethane) }\end{array}$ \\
\hline \multicolumn{2}{|l|}{ Chloramination } \\
\hline $\begin{array}{l}\text { Trihalomethanes (THMs), trihalonitromethanes } \\
\text { (with preozonation) }\end{array}$ & $\begin{array}{l}\text { Chloroform, bromoform, bromodichloromethane, dibromochloromethane, } \\
\text { nitromethane }\end{array}$ \\
\hline Haloacetic acids & $\begin{array}{l}\text { Monochloroacetic acid (chloroacetic acid), dichloroacetic acid, trichloroacetic } \\
\text { acid, bromoacetic acid (monobromoacetic acid), dibromoacetic acid, and } \\
\text { bromochloroacetic acid }\end{array}$ \\
\hline Halocarbonyls & $\begin{array}{l}\text { 1,1-dichloropropanone; 1,1,1-trichloropropanone } \\
\text { and trichloroacetaldehyde (chloral hydrate) }\end{array}$ \\
\hline Halonitriles & Cyanogen chloride, dichloroacetonitrile, and bromochloroacetonitrile \\
\hline Halofuranones & MX (3-chloro-4-[dichloromethyl]-5-hydroxy-2[5H]-furanone) and analogues \\
\hline \multicolumn{2}{|l|}{ Chlorination } \\
\hline THMs & The same as for chloramination plus some iodinated methanes \\
\hline Haloalkanes & Chloromethane, dichloromethane, and bromochloromethane \\
\hline Haloacetic acids & The same as for chloramination \\
\hline Other haloacids & $\begin{array}{l}\text { 2,2-dichloro-propanoic acid, 3,3-dichloropropenoic acid, and chloro- } \\
\text { hydroxy-dicarboxylic acid }\end{array}$ \\
\hline Halocarbonyls & $\begin{array}{l}\text { 1,1-dichloro-propanone, 1,1,1-trichloropropanone, 1,1-dichloro-2-butanone, } \\
\text { dichloro-acetaldehyde, and chloral hydrate }\end{array}$ \\
\hline Halonitriles & Haloacetonitriles plus others, including trichloropropenenitrile \\
\hline Halofuranones & MX and analogues, 5-hydroxy-5-trichloromethyl-2-furanone \\
\hline Halophenols & 2-chlorophenol \\
\hline
\end{tabular}

a Formed during ozonation in the presence of high bromide concentrations.

Note: This table shows representative disinfection by-products and is not an exhaustive list. The appearance of a compound on this list does not mean it is regulated. 


\section{Methods}

Our primary objective was to determine whether DBP-containing water contaminates food with which it comes into contact. We conducted controlled laboratory experiments to determine the partitioning of the target DBP contaminants (haloacetonitriles and HAAs) between food and water. We also performed simple food preparation and cooking experiments to evaluate food contamination under these controlled conditions.

\section{Determination of Disinfection By-Products in Water and Foods}

We determined the target DBPs, using the method for foods and beverages described in Raymer, Pellizzari, Childs, Briggs, and Shoemaker (2000). In brief, the method for determining HAAs in water consisted of adjusting the $\mathrm{pH}$ of 10 milliliters $(\mathrm{mL})$ of the water to $\mathrm{pH}=6.2$, adding a surrogate standard (2,3-dibromopropionic acid), and using methylt-butyl ether (MTBE) to extract neutral and basic analytes. We adjusted the $\mathrm{pH}$ of the aqueous layer to near zero, using concentrated sulphuric acid, and partitioned the acids into MTBE. Adding sulphuric acid in methanol and equilibration at $65^{\circ} \mathrm{C}$ for 3 hours formed the methyl ester derivatives of the acids. After we neutralized the solution using sodium bicarbonate, we added a quantitation standard and analyzed the extract, using gas chromatography with electron capture detection (GC/ECD). We then extracted the haloacetonitriles from a separate water aliquot using MTBE that was then back-extracted using sodium bicarbonate solution before GC/ECD analysis. The analysis of unboiled, spiked water served as a reference in each case. Method limits of detection for the haloacetonitriles and other neutral analytes were generally less than 1 part per billion ( $\mathrm{ppb}$ ) for aqueous samples.

We drained all foods, weighed them as soon as possible, homogenized them, and then extracted the HAAs as described previously. We added 2 grams of homogenate to $10 \mathrm{~mL}$ of water and then extracted and derivatized the HAAs as described for water. We determined the limits of detection to be in the low ppb range (Raymer et al., 2000).

\section{Stability of the Disinfection By-Products to Boiling}

Before conducting the experiments in which foods were cooked in DBP-containing water, we determined the stability of the target analytes during boiling to differentiate between compound decomposition and a lack of absorption into food during cooking. In separate experiments, we diluted haloacetonitriles (trichloroacetonitrile, dichloroacetonitrile, and bromochloroacetonitrile) and HAAs (monochloroacetic, monobromoacetic, dichloroacetic, trichloroacetic, bromochloroacetic, dibromoacetic, bromodichloroacetic, chlorodibromoacetic, and tribromoacetic acids) in methanol and added them to purified, or reagent, water (Milli-Q Integral System, Millipore, Billerica, Massachusetts) to provide spiking solution concentrations of $30 \mathrm{ppb}$ for haloacetonitriles and 50 to $500 \mathrm{ppb}$ for haloacetic acids. Chemicals were purchased from AccuStandard, Inc. (New Haven, Connecticut). Concentrations in the spiking solutions were such that the volumes of standards added were small, yet sufficiently large to be accurate and reproducible; hence, we would not expect the volume of solvent carrier to affect chemical behavior.

We brought the spiked waters to a boil in Pyrex beakers on a laboratory hot plate. Once each beaker of water came to a boil, we allowed it to boil for 5 minutes; we then removed it from the hot plate and allowed it to cool. We then added reagent water to return each water sample to its original volume to enable direct comparisons of haloacetonitrile and HAA concentrations without the need to use arithmetic corrections for water loss.

\section{Chemical Loss as a Function of Boiling Duration}

Because not all foods are cooked for the same length of time, the potential losses of the target DBPs from the water during boiling, either through volatilization into the air or chemical decomposition, must be characterized as a function of time. Knowledge of the kinetics of any changes is important in understanding the magnitudes of the potential exposure issues resulting from, for example, the preparation of a food that cooks for a few minutes (some vegetables) 
as compared with those that cook for several hours (stews).

We evaluated this factor by spiking haloacetonitriles and HAAs into $200 \mathrm{~mL}$ volumes of reagent water in Pyrex beakers and bringing the water to a boil, as previously described. We boiled aliquots (triplicate for each time point) for $10,20,30,40,50$, and 60 minutes before removing them from the heat to cool. In each case, we restored the boiled water samples to the $200 \mathrm{~mL}$ volume by adding reagent water and then extracted and analyzed the target analytes. The concentrations of the analytes extracted and determined in unboiled reagent water that was spiked to contain the same concentrations as those in boiled water provided a value that represented 100 percent recovery. The haloacetonitriles were not recovered after 10 minutes of boiling, which we anticipated from the initial experiment in which all target analytes were boiled for 5 minutes, so we dropped the haloacetonitriles from the food partitioning studies described next.

\section{Partition of Disinfection By-Products Into Foods During Cooking}

Even if tap water used to cook foods contains DBPs and the DBPs survive the boiling process, whether the DBPs actually partition into the food that will be consumed must be determined. This distinction matters, because if DBPs do not enter the food, then they will be drained away at the end of cooking and will have no effect on potential exposure. By contrast, if the foods that are subsequently ingested absorb all the DBPs, they can contribute to the consumer's amount of ingestion exposure, beyond what would result from consuming the regular daily amount of tap water alone.

We studied the partition of HAA DBPs into frozen carrots, frozen green beans, pinto beans, chicken, and pasta (regular spaghetti), after boiling in water that contained the HAAs of interest; we selected lettuce as another test food because it is commonly rinsed with water during preparation. People prepare pasta and dried beans with large volumes of water; with pasta, multiple contacts with drinking water are possible if the pasta is rinsed after cooking. Dried beans are usually soaked overnight, drained, and then cooked in fresh tap water. We selected all these foods because of their different cooking conditions and different chemical compositions (e.g., starch, vegetable, protein), and giving special attention to those commonly consumed by children.

We prepared all foods according to package directions, as applicable, using reagent water spiked with known HAA concentrations, which were selected to reflect the higher end of the concentrations reported in municipal water systems (Richardson, 1998; see Table 1). Foods processed identically but with unspiked reagent water served as controls. Because the foods might have already contained absorbed DBPs from contact with water during manufacturing and processing, we had to take these residues into account before calculating the absorption during these experiments. In each case, the total HAA mass for each analyte in the cooking water served as the maximum possible mass uptake (100 percent).

Some foods required additional contact with water after the initial preparation or cooking with water. We rinsed the cooked pasta with reagent water and with spiked water to determine whether rinsing caused additional HAA absorption. We cooked pinto beans in spiked water after soaking them in either spiked or reagent water. We boiled chicken in spiked water after a brief soaking in either reagent or spiked water to simulate rinsing of chicken prior to cooking. We soaked lettuce for approximately 5 minutes and then drained it before homogenization. We did not consider the rinsing of a food, such as chicken, followed by a nonboiling cooking method, such as grilling.

After all the food preparation, we compared HAA concentrations measured in food that was cooked in reagent water with concentrations in food cooked in spiked water. We tested significance by the $t$-test and the $F$ test, using SAS statistical software (SAS Institute, 2004). Differences between situations were considered statistically significant if the calculated $p$ values were less than 0.05 . 


\section{Results}

\section{Stability of the Disinfection By-Products During Boiling}

Haloacetonitriles were lost very rapidly when water was boiled. In fact, spiked water brought just to a boil and then cooled and analyzed showed no detectable residues. Figure 1 shows the recoveries of nine HAAs as a function of boiling time in spiked reagent water (initial concentrations ranged from 50 to $500 \mathrm{ppb}$ each).

The stability of HAAs in an aqueous solution brought to a boil showed that bromodichloroacetic, chlorodibromoacetic, and tribromoacetic acids were not recovered because they were rapidly lost during boiling; the recoveries fell to zero or close to zero at 10 minutes. This rapid loss of trihaloacetic acids is consistent with the fact that the trihalomethyl anion is a good leaving group, compared with a methyl group with fewer halogens. For this reason, it may lead to greater decomposition via decarboxylation of trihaloacetic acids than is the case for mono- and dihalo- analogues.
Chloroacetic acid, bromoacetic acid, dibromoacetic acid, bromochloroacetic acid, dichloroacetic acid, and trichloroacetic acid remained and could contribute to human exposure via ingestion. Bromoacetic acid and trichloracetic acid showed some loss over time, while the remaining acids were well-recovered after 1 hour of boiling.

These data generally show that cooking food for longer periods of time can reduce the excess exposures associated with the absorption of certain HAAs during cooking; however, some of the HAA DBPs appear stable to boiling, so boiled liquid (e.g., a soup or stock) would contain select HAAs at concentrations essentially the same as in the starting tap water used, and consumption of them could contribute to human exposure accordingly. This finding does assume that the HAAs, despite their thermal stability, do not react with surface functional groups on food, such as hydroxyl or amine groups, which could reduce their availability for absorption from the cooked food during digestion.

\section{Figure 1. Recoveries of haloacetic acids as a function of boiling time}

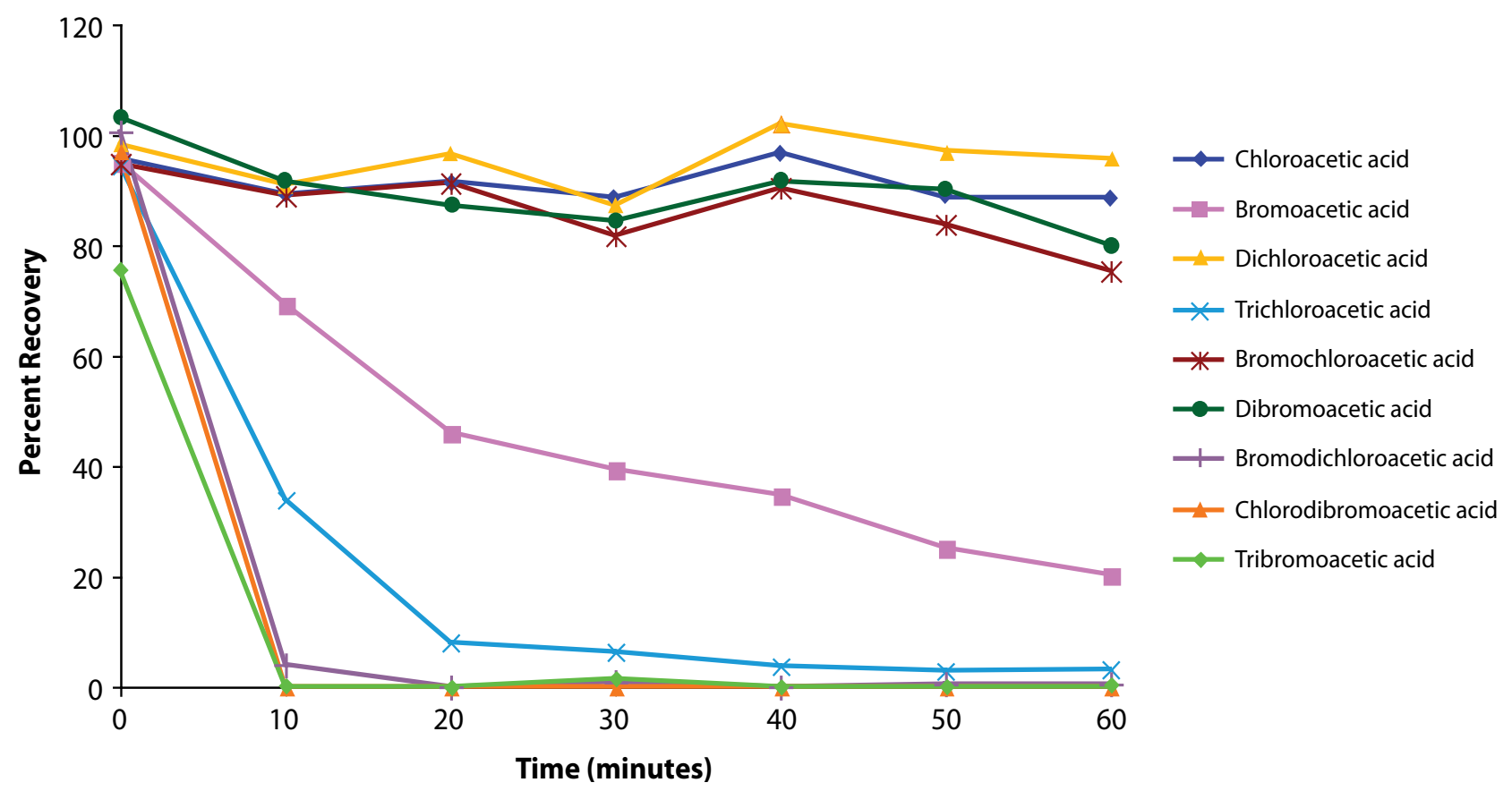




\section{Partition of Disinfection By-Products Into Foods During Cooking}

Foods cooked in reagent (nonspiked) water. The concentrations of HAAs cooked or soaked and then cooked in reagent water are shown in Table 2. Some HAAs were detectable in all the foods. Chloroacetic, dichloroacetic, and trichloroacetic acids were the HAAs most frequently detected at the highest concentrations.

Frozen green beans and carrots contained seven of the nine HAAs. We found similar quantities of dichloroacetic, trichloroacetic, and bromochloroacetic acids in chicken, lettuce, and pinto beans, although the source was not clear, especially for dried beans. Method blanks (aliquots of nonspiked reagent water taken through the extraction and analysis procedure) typically did not show HAA backgrounds at these levels; it is likely that these food items, as purchased, contained HAAs.
Foods cooked in spiked water. The HAA concentrations measured in foods after cooking in spiked water are shown in Table 3. We measured statistically significant uptakes for those acids not decomposed by boiling. For example, the uptake of dichloroacetic acid into cooked frozen carrots and cooked frozen green beans, expressed as the percentage of the total dichloroacetic acid available in the cooking water, was 64 percent and 48 percent, respectively.

Dibromoacetic acid was recovered from cooked frozen carrots and frozen green beans at 57 percent and 60 percent, respectively, again expressed as the total dibromoacetic acid available to the food during cooking. We recovered no chlorodibromoacetic or tribromoacetic acids, a finding consistent with the data in Figure 1 that showed rapid decomposition of these analytes during boiling.

Table 2. Concentrations of haloacetic acids found in foods cooked or soaked and cooked in reagent water

\begin{tabular}{|c|c|c|c|c|c|c|}
\hline Compound & $\begin{array}{l}\text { Chicken }^{\mathrm{a}} \\
(n=2)\end{array}$ & $\begin{array}{l}\text { Lettuce } \\
(n=1)\end{array}$ & $\begin{array}{l}\text { Frozen Green } \\
\text { Beans }(n=2)\end{array}$ & $\begin{array}{l}\text { Frozen Carrots } \\
\qquad(n=2)\end{array}$ & $\begin{array}{c}\text { Dried Pinto } \\
\text { Beans }^{\text {b }}(n=1)\end{array}$ & $\begin{array}{l}\text { Pastac } \\
(n=1)\end{array}$ \\
\hline Chloroacetic acid & $\mathrm{ND}(\mathrm{NC})$ & 54 & $56(4.7)$ & $82(4.8)$ & $\mathrm{ND}(\mathrm{NC})$ & ND \\
\hline Bromoacetic acid & ND & ND & $6.6(10)$ & $\mathrm{ND}(\mathrm{NC})$ & $\mathrm{ND}(\mathrm{NC})$ & ND \\
\hline Dichloroacetic acid & $31(3.1)$ & 54 & $90(1.4)$ & $100(4.5)$ & 42 & 33 \\
\hline Trichloroacetic acid & $32(27)$ & 34.0 & $81(3.3)$ & $84(3.2)$ & 19 & 35 \\
\hline Bromochloroacetic acid & $7.3(3.3)$ & 9.5 & $13(3.3)$ & $14(1.9)$ & 8.2 & 4.2 \\
\hline Dibromoacetic acid & ND & ND & $\mathrm{ND}(\mathrm{NC})$ & $3.3(2.8)$ & ND & ND \\
\hline Bromodichloroacetic acid & $11(4.1)$ & 15 & $17(2.9)$ & $11(8.9)$ & ND & 16 \\
\hline Chlorodibromoacetic acid & $5.5(7.7)$ & ND & $\mathrm{ND}(\mathrm{NC})$ & $\mathrm{ND}(\mathrm{NC})$ & ND & ND \\
\hline Tribromoacetic acid & ND & ND & $16(15)$ & $5.1(\mathrm{NC})$ & ND & ND \\
\hline
\end{tabular}

$\mathrm{ND}=$ not detected in the sample; $\mathrm{NC}=$ not calculated.

a Values from raw chicken that was soaked in reagent water before cooking.

b Pinto beans were soaked in reagent water and then cooked in reagent water.

c Pasta was cooked in reagent water and was not rinsed.

Notes: Concentrations in nanograms per gram; numbers in parentheses represent percent relevant standard deviation. 
The results for pasta are shown in Table 4. Although we could not calculate the statistical significance of the uptakes after cooking ( $\mathrm{n}=1$ for pasta cooked in unspiked water), we observed that HAA uptake occurred for all HAAs except chlorodibromoacetic and bromodichloroacetic acids. The values for the remaining HAAs ranged from 2 percent to 11 percent. Rinsing the cooked pasta in reagent water did not significantly reduce the HAAs absorbed during cooking in HAA-containing water (data not shown). When rinsed in spiked water, pasta cooked in reagent water absorbed 6.1 to 10 percent of the HAAs available in the rinse water, including those HAAs decomposed during boiling. Statistically significant HAA uptakes from HAA-containing rinse water resulted in an additional 5.4 percent to 7 percent uptake above the HAAs absorbed when cooking was done in spiked water (last column of Table 4).

Table 3. Percentage absorption of haloacetic acids into foods during cooking

\begin{tabular}{|c|c|c|c|c|c|c|}
\hline \multirow[b]{2}{*}{ Compound } & \multirow{2}{*}{$\begin{array}{l}\text { Concentration } \\
\text { in Water } \\
(\mathbf{p p b})\end{array}$} & \multicolumn{5}{|c|}{ Percent Uptake (Percent Relevant Standard Deviation) } \\
\hline & & $\begin{array}{l}\text { Frozen } \\
\text { Carrots }\end{array}$ & $\begin{array}{c}\text { Frozen Green } \\
\text { Beans }\end{array}$ & $\begin{array}{l}\text { Dried Pinto } \\
\text { Beans }^{\mathrm{a}}\end{array}$ & Chicken $^{\mathrm{a}}$ & Lettuce $^{b}$ \\
\hline Chloroacetic acid & 500 & ND & $17(38)^{*}$ & $62(3.1)^{c}$ & $15(3.2)^{*}$ & $2.5(42)^{c}$ \\
\hline Bromoacetic acid & 100 & $57(3.8)^{*}$ & $21(50)$ & ND & ND & $4.5(9.1)^{\mathrm{C}}$ \\
\hline Dichloroacetic acid & 150 & $64(24)^{*}$ & $48(39)^{*}$ & $85(3.4)^{c}$ & $11(22)^{*}$ & $3.9(19)^{c}$ \\
\hline Trichloroacetic acid & 50 & $24(290)$ & $33(92)$ & INT & $14(120)^{*}$ & $3.1(75)^{c}$ \\
\hline Bromochloroacetic acid & 100 & $40(9.7)^{*}$ & $35(8.0)^{*}$ & $37(5.0)^{c}$ & $7.1(45)^{*}$ & $4.2(5.4)^{\mathrm{c}}$ \\
\hline Dibromoacetic acid & 50 & $57(8.0)^{*}$ & $60(18)^{*}$ & $51(16)^{c}$ & $11.0(23.0)^{*}$ & $7.2(6.7)^{c}$ \\
\hline Bromodichloroacetic acid & 100 & $26.0(43)^{*}$ & $2.2(180)$ & $5.3(87)^{\mathrm{c}}$ & ND & $1.8(40)^{\mathrm{c}}$ \\
\hline Chlorodibromoacetic acid & 100 & ND & ND & ND & ND & $6.5(5.5)^{*}$ \\
\hline Tribromoacetic acid & 100 & ND & ND & ND & ND & $7.8(12)^{c}$ \\
\hline
\end{tabular}

${ }^{*} p<.05 . \mathrm{ND}=$ not detected; INT = chromatographic interference that precluded quantitation of the analyte.

a Pinto beans soaked in reagent water and cooked in water spiked with HAAs; chicken soaked and cooked in spiked water.

b Lettuce soaked for 5 minutes in water containing HAAs.

c The $p$ value was not calculated because $n=1$ for the control case; a substantial increase was noted for these compounds, as compared with the food cooked in reagent water.

Notes: Uptake $=$ (HAA mass in food cooked in spiked water - HAA mass in food cooked in reagent water) $\times 100 \div$ (total HAA mass in cooking water); $n=3$.

Table 4. Absorption of haloacetic acids after cooking in spiked water and the effect of rinsing pasta

\begin{tabular}{|c|c|c|c|}
\hline \multirow[b]{2}{*}{ Compound } & \multirow{2}{*}{$\begin{array}{c}\text { Pasta Not Rinsed After Cooking } \\
\text { Percent Uptake } \\
\text { From Cooking } \\
\text { (\%RSD) }\end{array}$} & \multicolumn{2}{|c|}{ Pasta Rinsed with Spiked Water After Cooking } \\
\hline & & $\begin{array}{c}\text { Percent Uptake from Rinse by } \\
\text { Pasta Cooked in Reagent Water } \\
\text { (\%RSD) }\end{array}$ & $\begin{array}{c}\text { Percent Uptake from Rinse by } \\
\text { Pasta Cooked in Spiked Water } \\
\text { (\%RSD) }\end{array}$ \\
\hline Chloroacetic acid & $7.8(6.1)^{\mathrm{a}}$ & $7.7(16)^{\mathrm{a}}$ & $6.8(3.6)^{*}$ \\
\hline Bromoacetic acid & $2.8(8.7)^{\mathrm{a}}$ & $6.1(9.5)^{\mathrm{a}}$ & $5.4(6.1)^{*}$ \\
\hline Dichloroacetic acid & $11(14)^{\mathrm{a}}$ & $7.7(2.3)^{\mathrm{a}}$ & $7.0(11)^{*}$ \\
\hline Trichloroacetic acid & $5.9(21)^{\mathrm{a}}$ & $9.2(2.9)^{\mathrm{a}}$ & $8.3(12)$ \\
\hline Bromochloroacetic acid & $9.6(12)^{a}$ & $8.0(2.5)^{\mathrm{a}}$ & $6.7(8.4)^{*}$ \\
\hline Dibromoacetic acid & $8.9(12)^{a}$ & $7.8(8.1)^{a}$ & $6.6(6.4)^{*}$ \\
\hline Bromodichloroacetic acid & ND & $8.6(0.1)^{a}$ & $6.1(8.0)^{*}$ \\
\hline Chlorodibromoacetic acid & ND & $9.8(1.8)^{\mathrm{a}}$ & $6.9(6.5)^{*}$ \\
\hline Tribromoacetic acid & $2.0(16)^{a}$ & $10(1.5)^{\mathrm{a}}$ & $6.2(9.6)^{*}$ \\
\hline
\end{tabular}

${ }^{*} p<.05 ; \mathrm{ND}=$ not detected; $\% \mathrm{RSD}=$ percent relative standard deviation.

a The $p$ value was not calculated, because $n=1$ for control case (pasta cooked in reagent water); a substantial increase was noted for these compounds, as compared with the food cooked in reagent water.

Notes: Uptake calculations corrected for background (i.e., concentrations of haloacetic acids measured after cooking in reagent water); $n=3$ in each case. 


\section{Discussion}

We designed this study to determine the extent to which home cooking of foods using DBP-containing water could increase ingestion exposures above those realized by ingesting the DBP-containing water alone. We studied the stability of DBPs to boiling and the extent of their absorption from water used to cook foods.

Our tests of the stability of HAAs in an aqueous solution brought to a boil showed that bromodichloroacetic, chlorodibromoacetic, and tribromoacetic acids were not recovered, which suggests that excess exposures to these acids in boiled foods are minimal. Bromoacetic acid and trichloroacetic acid showed some loss over time, which suggests that boiling duration will affect excess dietary exposure to these acids. Chloroacetic acid, bromoacetic acid, dibromoacetic acid, bromochloroacetic acid, dichloroacetic acid, and trichloroacetic acid remained; therefore, these DBPs can contribute to excess human exposure via ingestion, even after lengthy periods of cooking.

Because some of the HAAs appeared in foods boiled in nonspiked reagent water, we suspected that HAAs might arise from water used during food processing for packaging. Indeed, conversations with the manufacturer confirmed that, at least for carrots, significant amounts of tap water are used to prepare them for packaging. Green beans likely undergo similar handling. Pasta manufacturing also uses water. Thus, processed foods likely contain HAAs as purchased, although these HAAs contribute very little to the excess dietary exposure.

In our tests the partition of HAA DBPs into frozen carrots, frozen green beans, pinto beans, chicken, and pasta after boiling and into lettuce after contact with water showed that absorption of individual HAAs available from water ranged from minimal to as much as 85 percent, depending on the food and the HAA. The HAAs showing the greatest extent of uptake were bromoacetic, dichloroacetic, bromochloroacetic, and dibromoacetic acids. Initial rinsing of the chicken and the soaking of the pinto beans in spiked water did not result in any significant increases in HAA concentration when the foods were subsequently cooked in spiked water (data not shown), which suggests that contact with HAA-containing water prior to cooking is not an important exposure pathway.

In general, we did not detect chlorodibromoacetic and tribromoacetic acids in the foods after cooking. This result is consistent with the rapid loss of these two compounds from boiling water. Soaking lettuce also resulted in absorption of HAAs at levels between 1.8 percent and 7.8 percent of the total available from the soaking water.

The results for pasta indicated that as much as 11 percent of the available HAAs were either absorbed or adsorbed during cooking in spiked water. Because of the large volumes of water used to cook pasta, the masses of HAAs absorbed can be much higher than for other types of food. In addition, the data on uptake after rinsing with spiked water indicated that additional amounts of HAAs, up to 10 percent, are absorbed from the rinsing water. This finding held, whether the pasta was cooked in reagent water or was cooked in spiked drinking (tap) water, which indicates that other organic substances in regular drinking water, as opposed to clean reagent water, did not impact the partition of DBP contaminants into the food. The HAAs that typically showed low recovery after cooking (bromodichloroacetic, chlorodibromoacetic, and tribromoacetic acids) became available to contribute to exposure after contact of the pasta with fresh DBPcontaining tap water.

In order to help place our findings in context, we compared the measured uptakes (excess dietary exposure) to exposures anticipated if tap water that contains HAAs at the EPA regulatory limit were used for cooking. Current EPA regulation for the sum of five HAAs (HAA5; monochloroacetic, dichloroacetic, trichloroacetic, monobromoacetic, and dibromoacetic acids) in drinking water establishes a limit of 60 micrograms ( $\mu \mathrm{g}$ ) per liter (Richardson, 2005). At a consumption rate of 2 liters (L) a day, assumed by EPA for estimating exposures (U.S. Environmental Protection Agency, 1997), at the $60 \mu \mathrm{g} / \mathrm{L}$ limit for an adult, the total mass of HAAs ingested would be $120 \mu \mathrm{g} /$ day. However, if people use the same tap water to cook foods, then they could experience an 
exposure above that amount upon ingestion of the cooked food. For example, if four servings of green beans are cooked in $0.5 \mathrm{~L}$ of water at the HAA5 limit and if the beans absorb 50 percent of the HAAs, then the food-related dose of HAAs is $0.5 \mathrm{~L} \mathrm{x} 60 \mu \mathrm{g} / \mathrm{L} \mathrm{x} 0.5$ fractional uptake $/ 4$ servings $=3.75 \mu \mathrm{g}$ of HAA5 per serving. This calculation neglects any HAAs already in the food as purchased. In this case, however, the excess exposure from food is not a major contributor to the total, presumably safe, exposure from tap water alone.

Using the same logic, if two servings of spaghetti are cooked in $2 \mathrm{~L}$ of water at the HAA5 limit and if the pasta absorbs 10 percent of the total HAA mass available from the cooking water, then the additional HAAs consumption is equal to $2 \mathrm{~L}$ x $60 \mu \mathrm{g} / \mathrm{L}$ x 0.1 fractional uptake/2 servings, or $6 \mu \mathrm{g}$ of HAA 5 per serving. This value neglects any additional HAA uptake if the pasta is rinsed.

Consideration of some limitations to this study is warranted and may inform future research. Whether, in our analyses, the haloacetonitriles were lost to volatilization or decomposed during the heating process is not clear. Exposures to haloacetonitriles via foods that are boiled in drinking water are likely to be minimal; we did not, however, investigate exposures to possible degradation products of haloacetonitriles. Another potentially important consideration for pasta is the food surface area per unit mass. We used "regular" spaghetti; however, the surface area of a serving of angel hair pasta is higher than that for the same mass of fettuccini; this factor could well affect the absorption of HAAs: If HAAs are adsorbed onto the surface, then a decrease in surface area could reduce absorption; if, on the other hand, the HAAs penetrate into the pasta matrix as water is absorbed, then the total HAA mass absorbed may be independent of the surface area per unit mass. We did not investigate these possibilities.

Our results show that consumption of foods cooked in water containing HAAs can result in an approximate exposure increase of a few micrograms over the levels that people would experience if drinking water were their sole exposure pathway. The type and amount of increased exposure will depend on the type of food and the volume of water used to cook it. Alternatively, many foods, including vegetables and rice, can be steamed, rather than boiled. Doing so would likely reduce the uptake of dissociated HAAs because they are not volatile if dissociated and would not migrate into the steam. We did not evaluate this possibility in this study. However, volatile DBPs, including trihalomethanes and, perhaps, haloacetonitriles may be absorbed from steam. This possibility should be investigated. Because HAAs in tap water can increase the potential for human exposure if people use such water to boil foods during cooking, regulators should consider this excess dietary exposure when defining the acceptable quantities of DBPs, at least for HAAs, in drinking water. 


\section{References}

Hua, G., \& Reckhow, D. A. (2007). Comparison of disinfection byproduct formation from chlorine and alternative disinfectants. Water Resources, 41(8), 1667-1678.

King, W. D., Dodds, L., Armson, B. A., Allen, A. C., Fell, D. B., \& Nimrod, C. (2004). Exposure assessment in epidemiologic studies of adverse pregnancy outcomes and disinfection byproducts. Journal of Exposure Analysis and Environmental Epidemiology, 14(6), 466-472.

Krasner, S. W. (1996). The effects of ozonation, biofiltration, and secondary disinfection on DBP formation. In Water quality technology conference proceedings. Symposium conducted at the meeting of the American Water Works Association, Denver, CO.

Krasner, S. W., Weinberg, H. S., Richardson, S. D., Pastor, S. J., Chinn, R., Sclimenti, M. J., et al. (2006). Occurrence of a new generation of disinfection byproducts. Environmental Science and Technology, 40(23), 7175-7185.

Moser, V. C., Phillips, P. M., Levine, A. B., McDaniel, K. L., Sills, R. C., Jortner, B. S., et al. (2004). Neurotoxicity produced by dibromoacetic acid in drinking water of rats. Toxicological Sciences, 79(1), 112-122.

Muellner, M. G., Wagner, E. D., McCalla, K., Richardson, S. D., Woo, Y. T., \& Plewa, M. J. (2007). Haloacetonitriles vs. regulated haloacetic acids: Are nitrogen-containing DBPs more toxic? Environmental Science and Technology, 41(2), 645-651.

Nicholson, B. C. (1994). Disinfection and water treatment: Formation of chemical by-products. Water (Supplement), 21(4), 14-16.

Raymer, J. H., Pellizzari, E., Childs, B., Briggs, K., \& Shoemaker, J. A. (2000). Analytical methods for water disinfection byproducts in foods and beverages. Journal of Exposure Analysis and Environmental Epidemiology, 10(6, Pt. 2), 808-815.
Richardson, S. D. (1998). Identification of drinking water by-products. In R. A. Meyers (Ed.), Encyclopedia of environmental analysis and remediation (Vol. 3, pp. 1398-1421). New York: Wiley.

Richardson, S. D. (2005). New disinfection byproduct issues: Emerging DBPS and alternative routes of exposure. Global NEST Journal, 7(1), 43-60.

Richardson, S. D., Thruston, A. D., Jr., Rav-Acha, C., Groisman, L., Popilevsky, I., Juraev, O., et al. (2003). Tribromopyrrole, brominated acids, and other disinfection byproducts produced by disinfection of drinking water rich in bromide. Environmental Science and Technology, 37(17), 3782-3793.

SAS Institute (2004). SAS/STAT (Version 9.1) [Statistical software]. Cary, NC: SAS Institute.

Symons, J. M., Speitel, G. E., Jr., Hwang, C. J., Krasner, S. W., Barrett, S. E., Diehl, A. C., et al. (1996). Factors affecting disinfection by-product formation during chloramination. In Water quality technology conference proceedings. Symposium conducted at the meeting of the American Water Works Association, Denver, CO.

U.S. Environmental Protection Agency (1997). Exposure factors handbook volume II, food ingestion factors (EPA/600/P-95/002Fb). Washington, DC: Office of Research and Development.

Villanueva, C. M., Cantor, K. P., Cordier, S., Jaakkola, J. J., King, W. D., Lynch, C. F., et al. (2004). Disinfection byproducts and bladder cancer: A pooled analysis. Epidemiology, 15(3), 357-367.

von Gunten, U. (2007). The basics of oxidants in water treatment. Part B: Ozone reactions. Water Science and Technology, 55(12), 25-29.

Weisel, C. P., Kim, H., Haltmeier, P., \& Klotz, J. B. (1999). Exposure estimates to disinfection by-products of chlorinated drinking water. Environmental Health Perspectives, 107(2), 103110. 


\section{Acknowledgments}

This research was supported by US Environmental Protection Agency (EPA) Science to Achieve Results (STAR) grant R826836-01 (food uptake studies) and EPA contract 68-C5-0011 (haloacetic acids stability studies). This work has not been subjected to EPA review, and no endorsement should be inferred. The authors would also like to thank Jody Shoemaker, PhD, of EPA, and Gerry Akland, MS, formerly of RTI, for useful discussions about this work and Tom Marrero, PhD, formerly of RTI, Michelle S. McCombs and D. Keith Briggs, both of RTI, and David White and Brenda Childs, formerly of RTI, for their diligent laboratory contributions. 
RTI International is an independent, nonprofit research organization dedicated to improving the human condition by turning knowledge into practice. RTI offers innovative research and technical solutions to governments and businesses worldwide in the areas of health and pharmaceuticals, education and training, surveys and statistics, advanced technology, international development, economic and social policy, energy and the environment, and laboratory and chemistry services.

The RTI Press complements traditional publication outlets by providing another way for RTI researchers to disseminate the knowledge they generate. This PDF document is offered as a public service of RTI International. More information about RTI Press can be found at www.rti.org/rtipress. 